\title{
A Emenda Constitucional 95: empecilhos para cumprir o PNE
}

Constitutional amendment 95

obstacles to meeting the PNE

La Enmienda Constitucional 95:

obstáculos para cumplir con el PNE

\section{GIL VICENTE REIS DE FIGUEIREDO*}

Universidade Federal de São Carlos, São Carlos- SP, Brasil.

\begin{abstract}
RESUMO: $\mathrm{O}$ artigo analisa a evolução do número de matrículas na educação infantil/creche, comparando-a com o previsto na Meta 1 do Plano Nacional de Educação (PNE), aprovado em 2014, cujo objetivo é "ampliar a oferta de educação infantil em creches de forma a atender, no mínimo, $50 \%$ das crianças de até 3 anos" até o final de sua vigência. Faz estimativa do necessário para cumprir o PNE, do ponto de vista da Meta 17, e para garantir a valorização dos/as profissionais do magistério das redes públicas de educação básica de forma a equiparar seu rendimento médio ao dos demais profissionais com escolaridade equivalente. Demonstra que nenhuma dessas metas vem sendo cumprida, comprometendo a oferta prevista e o nível de investimento por aluno/ ano, impedindo a implantação do custo aluno-qualidade.

Palavras-chave: Plano Nacional de Educação. Custo aluno-qualidade. Financiamento da educação básica.'
\end{abstract}

\begin{abstract}
The article analyzes the evolution of the number of enrollments in kindergarten / day care, comparing it with what is foreseen in Goal 1 of the National Education Plan (PNE), approved in 2014,
\end{abstract}

* Engenheiro de Telecomunicações (IME); PhD em Matemática (University of Warwick, Inglaterra); diversos pós-doutorados (IMPA). Foi: pesquisador na University of Sussex (Inglatera), Coordenador dos Programas de Pós-Graduação em Matemática, na COPPE-UFRJ e em diversas Universidades; professor da UnB, USP e UFSCar; Pró-reitor de Administração e Planejamento da UFSCar; presidente do Fórum Nacional de Pró-reitores de Administração e Planejamento das IFES (FORPLAD); assessor da FAPESP; pesquisador do CNPq; publicações nas áreas de matemática e educação; membro titular do FNE; Presidente do PROIFES. É um dos atuais dirigentes do FNPE e Diretor de Relações Internacionais do PROIFES, atuando na Internacional de Educação (IE). E-mail: <gvrf2011@gmail.com>. 
whose goal is "to expand the offer of kindergarten in nurseries in order to attend at least $50 \%$ of children under 3 years of age "until the end of their term. It makes an estimate of what is necessary to fulfill the PNE, from the point of view of Goal 17, and to ensure the valorization of the teachers of the public schools of basic education in order to equate their average income with the other professionals with equivalent education. It demonstrates that none of these goals has been met, compromising the planned offer and the level of investment per student / year, preventing the implementation of Cost of Quality Education per Student.

Keywords: National Education Plan. Cost of Quality Education per Student . Financing of basic education.

RESUMEN: El artículo analiza la evolución del número de inscripciones en educación infantil/guardería, comparándolo con lo previsto en el Objetivo 1 del Plan Nacional de Educación (PNE), aprobado en 2014, cuyo objetivo es "ampliar la oferta de educación infantil en guarderías para atender al menos al 50\% de los niños menores de 3 años "hasta el final de su vigencia. Hace una estimación de lo que es necesario para cumplir con el PNE, desde el punto de vista del Objetivo 17, y para garantizar la valorización de los docentes de las escuelas públicas de educación básica para equiparar sus ingresos promedio con los otros profesionales con educación equivalente. Muestra que ninguno de estos objetivos se ha cumplido, comprometiendo el suministro esperado y el nivel de inversión por estudiante / año, evitando la implementación del Costo Alumno-Calidad.

Palabras clave: Plan Nacional de Educación. Costo Alumno-Calidad. Financiación de la educación básica.

\section{Introdução}

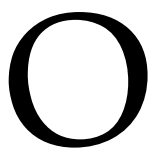

Plano Nacional de Educação (PNE), aprovado em 2014, previa aportes crescentes de recursos para a educação, de forma a alcançar 10\% do PIB ao final de sua vigência (2024). Com a aprovação, em 2016, da Emenda Constitucional 95 (EC 95), entretanto, a destinação de verbas públicas para os setores sociais foi fortemente restringida, afetando também a educação. A partir daí a área vem sofrendo seguidos cortes de verbas, impossibilitando a implantação do PNE, tanto nos aspectos 
quantitativos previstos em suas diversas metas, quanto no que se refere à implantação do custo aluno-qualidade ${ }^{1}$. Isso porque, com o declínio progressivo e agudo do financiamento público, têm sido reduzidos os "insumos indispensáveis ao processo de ensino-aprendizagem", dentre os quais um dos mais importantes é o relativo ao pagamento de salários compatíveis com a valorização dos professores, conforme previsto na Meta $17^{2}$ daquele Plano.

Analisaremos, de início, a título de exemplo ilustrativo, a evolução do número de matrículas na educação infantil/creche, comparando-a com o indicado pela Meta $1^{3}$ do $\mathrm{PNE}$, considerados os dados do $\mathrm{IBGE}^{4}$ referentes à população brasileira na faixa etária de 0 a 3 anos. A fonte para o número de matrículas na educação infantil/creche é o Inep/ $\mathrm{MEC}^{5}$. Além disso, apresentaremos a estimativa da evolução do investimento aluno/ano (educação infantil/creche), baseado em dados do Inep/MEC (2000-2015) e nos valores do piso salarial docente (até 2019), conforme metodologia a ser explicitada. Essa estimativa será comparada com projeções compatíveis com a Meta 17, feitas a partir dos dados contidos na Nota Técnica Número 141/outubro de 2014, do Departamento Intersindical de Estatística e Estudos Socioeconômicos (Dieese) ${ }^{6}$.

A conclusão é que há um descumprimento progressivo da Meta 1, no tocante à educação infantil/creche; ao mesmo tempo, a forte elevação dos investimentos por aluno/ ano verificada em governos anteriores dá lugar a uma total estagnação - inteiramente incompatível com a Meta 17. Elementos da política econômica do atual Governo impedem da mesma forma a consecução das demais metas do PNE.

\section{A oferta de matrículas na educação Infantil/Creche e a Meta 1}

A Meta 1 do PNE prevê a elevação gradativa da oferta de educação infantil/creche, de modo a alcançar, em 2024 (após 10 anos de vigência do PNE), 50\% da população na faixa 0-3 anos de idade.

Antes de analisar o ritmo atual de crescimento da oferta relativa à Meta 1, creche, vale uma pequena digressão, para ressaltar dois pontos em que o PNE mereceria ter sido mais detalhado.

O primeiro refere-se à falta de uma diretriz para a redução progressiva das disparidades regionais na oferta de vagas - não apenas na educação infantil/creche, mas em todos os outros níveis, etapas e modalidades. Para que se tenha a dimensão da importância dessa questão, basta mencionar que, em 2018, a média nacional da oferta de educação infantil/creche (ver Quadro 1, abaixo) situava-se em 31,8\% da faixa etária; entretanto, na Região Norte, esse percentual não chegava a $18 \%$, enquanto que, na Região Sul, ultrapassava 37\%. É verdade que a redução de disparidades chegou a ser tratada no PNE. A estratégia 1.2), por exemplo, apontou para a redução - máximo de $10 \%$, ao final da 
vigência do PNE - dos diferenciais entre as taxas de frequência relativas ao quinto de renda familiar per capita mais elevado e o quinto com renda familiar per capita mais baixo; entretanto, nenhuma das estratégias da Meta 1 indicou parâmetros para a redução dos diferenciais das taxas de frequência, do ponto de vista geográfico.

O segundo ponto diz respeito à falta de menção específica a metas de investimento por aluno/ano, tanto no caso específico da educação infantil/creche como nos demais, de forma a integrar a Meta 20, global, que aponta para 10\% do PIB ao final da vigência do PNE, como as demais metas.

O Quadro 1 mostra a evolução da oferta pública e privadada educação infantil/creche, no período 2002-2018, de acordo com os censos escolares divulgados pelo Inep/ MEC. Já o Quadro 2 mostra uma estimativa da oferta pública necessária para que se alcance, em 2024, os 50\% da população na faixa etária 0-3 anos. Para isso, adotamos algumas hipóteses:

1. a oferta privada, no período 2019-2024, seguirá se expandindo na mesma velocidade que no período 2015-2018 (crescimento médio de 3,72\%/ano);

2. a oferta pública garantirá o cumprimento da Meta 1 , complementando a oferta privada existente;

3. a evolução da população na faixa etária 0-3 anos seguirá as projeções do IBGE (conforme as projeções publicadas pelo Instituto em 2013); e

4. a oferta será ampliada de forma linear, no período (2015-2024).

\section{Quadro 1 - Educação infantil/creche}

\begin{tabular}{|c|c|c|c|c|c|c|c|}
\hline Ano & Pública & Privada & Total & Pop. 0 - 3 a & \% Pública & \% Privada & \% Total \\
\hline 2002 & 773.964 & 435.204 & 1.209 .168 & 13.856 .625 & $5,6 \%$ & $3,1 \%$ & $8,7 \%$ \\
\hline 2003 & 767.505 & 470.053 & 1.237 .558 & 13.787 .292 & $5,6 \%$ & $3,4 \%$ & $9,0 \%$ \\
\hline 2004 & 844.066 & 504.171 & 1.348 .237 & 13.682 .213 & $6,2 \%$ & $3,7 \%$ & $9,9 \%$ \\
\hline 2005 & 879.117 & 535.226 & 1.414 .343 & 13.501 .658 & $6,5 \%$ & $4,0 \%$ & $10,5 \%$ \\
\hline 2006 & 917.460 & 510.482 & 1.427 .942 & 13.317 .664 & $6,9 \%$ & $3,8 \%$ & $10,7 \%$ \\
\hline 2007 & 1.050 .295 & 529.286 & 1.579 .581 & 13.130 .205 & $8,0 \%$ & $4,0 \%$ & $12,0 \%$ \\
\hline 2008 & 1.143 .430 & 608.306 & 1.751 .736 & 12.940 .918 & $8,8 \%$ & $4,7 \%$ & $13,5 \%$ \\
\hline 2009 & 1.252 .765 & 643.598 & 1.896 .363 & 12.751 .943 & $9,8 \%$ & $5,0 \%$ & $14,9 \%$ \\
\hline 2010 & 1.353 .736 & 710.917 & 2.064 .653 & 12.565 .553 & $10,8 \%$ & $5,7 \%$ & $16,4 \%$ \\
\hline 2011 & 1.470 .507 & 828.200 & 2.298 .707 & 12.383 .237 & $11,9 \%$ & $6,7 \%$ & $18,6 \%$ \\
\hline 2012 & 1.611 .054 & 929.737 & 2.540 .791 & 12.206 .152 & $13,2 \%$ & $7,6 \%$ & $20,8 \%$ \\
\hline
\end{tabular}




\begin{tabular}{|c|c|c|c|c|c|c|c}
\hline Ano & Pública & Privada & Total & Pop. 0 - 3 a & \% Pública & \% Privada & \% Total \\
\hline 2013 & 1.730 .877 & 999.242 & 2.730 .119 & 12.035 .305 & $14,4 \%$ & $8,3 \%$ & $22,7 \%$ \\
\hline 2014 & 1.830 .291 & 1.061 .685 & 2.891 .976 & 11.871 .370 & $15,4 \%$ & $8,9 \%$ & $25,4 \%$ \\
\hline 2015 & 1.936 .614 & 1.106 .934 & 3.043 .548 & 11.714 .289 & $16,5 \%$ & $9,4 \%$ & $26,0 \%$ \\
\hline 2016 & 2.081 .924 & 1.151 .815 & 3.233 .739 & 11.563 .648 & $18,0 \%$ & $10,0 \%$ & $28,0 \%$ \\
\hline 2017 & 2.226 .173 & 1.180 .623 & 3.406 .796 & 11.418 .828 & $19,5 \%$ & $10,3 \%$ & $29,8 \%$ \\
\hline 2018 & 2.352 .032 & 1.235 .260 & 3.587 .292 & 11.279 .139 & $20,9 \%$ & $11,0 \%$ & $31,8 \%$ \\
\hline
\end{tabular}

Fonte: Censo Escolar, 2002 - 2018 (Inep)

\section{Quadro 2 - Estimativa da evolução da oferta de matrículas, de forma a atingir a meta 1 em 2024}

Hipótese 1: A Meta 1 será garantida pela oferta na esfera pública.

Hipótese 2: A população será a prevista pelo IBGE ('Projeções 2013').

Hipótese 3: A oferta privada crescerá no período 2019-2024 no mesmo ritmo que em 2015-2018.

\begin{tabular}{|c|c|c|c|c|c|c|c|}
\hline Ano & Pública & Privada & Total & Pop. 0 - 3 a & \% Públ. & \% Priv. & \% total \\
\hline 2015 & 2.022 .112 & 1.106 .934 & 3.129 .046 & 11.714 .289 & $17,3 \%$ & $9,4 \%$ & $26,7 \%$ \\
\hline 2016 & 2.214 .301 & 1.151 .815 & 3.366 .116 & 11.563 .648 & $19,1 \%$ & $10,0 \%$ & $29,1 \%$ \\
\hline 2017 & 2.422 .562 & 1.180 .623 & 3.603 .185 & 11.418 .828 & $21,2 \%$ & $10,3 \%$ & $31,6 \%$ \\
\hline 2018 & 2.604 .995 & 1.235 .260 & 3.840 .255 & 11.279 .139 & $23,1 \%$ & $11,0 \%$ & $34,0 \%$ \\
\hline 2019 & 2.796 .065 & 1.281 .260 & 4.077 .325 & 11.144 .025 & $25,1 \%$ & $11,5 \%$ & $36,6 \%$ \\
\hline 2020 & 2.985 .422 & 1.328 .973 & 4.314 .395 & 11.013 .203 & $27,1 \%$ & $12,1 \%$ & $39,2 \%$ \\
\hline 2021 & 3.173 .002 & 1.378 .463 & 4.551 .465 & 10.886 .636 & $29,1 \%$ & $12,7 \%$ & $41,8 \%$ \\
\hline 2022 & 3.358 .739 & 1.429 .795 & 4.788 .534 & 10.763 .747 & $31,2 \%$ & $13,3 \%$ & $44,5 \%$ \\
\hline 2023 & 3.542 .564 & 1.483 .040 & 5.025 .604 & 10.643 .541 & $33,3 \%$ & $13,9 \%$ & $47,2 \%$ \\
\hline 2024 & 3.724 .407 & 1.538 .267 & 5.262 .674 & 10.525 .348 & $35,4 \%$ & $14,6 \%$ & $50,0 \%$ \\
\hline
\end{tabular}

Uma comparação entre o Quadro 1 e o Quadro 2 mostra que a oferta, no período pós-aprovação do PNE, não tem seguido o ritmo previsto. Vê-se que, em 2018, teria sido necessária a oferta pública de 2.604.995 vagas, enquanto foram ofertadas apenas 2.352.032 - um déficit de mais 250.000 vagas.

OGráfico 1 ilustra essa situação; a continuar o ritmo atual, fica evidente que o quantitativo previsto na Meta 1 não será alcançado em 2024. 


\section{Gráfico 1 - Matrículas EI-Creche: PNE x INEP}

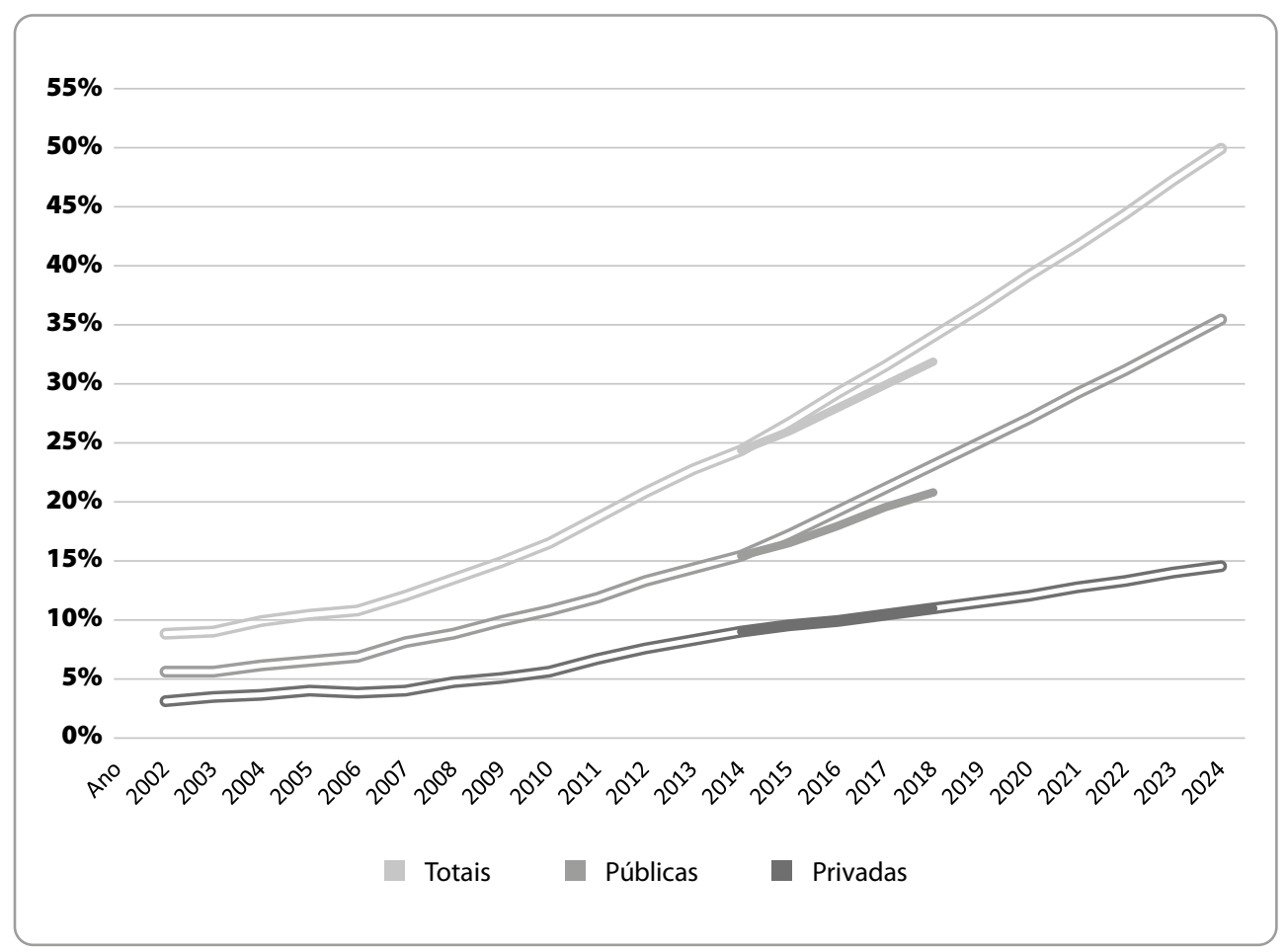

\section{O investimento necessário para cumprir a Meta 17}

Para acompanhar a Meta 17 do PNE (2014) é necessário definir, do ponto de vista técnico, o que dever ser feito exatamente para "valorizar os(as) profissionais do magistério das redes públicas de educação básica de forma a equiparar seu rendimento médio ao dos(as) demais profissionais com escolaridade equivalente".

Em primeiro lugar, mencionemos um documento que permite resolver a questão. Trata-se da Nota Técnica 141 do Dieese (09/2014), que em sua Tabela $10^{7}$ mostra que a "variação necessária para equiparar a remuneração docente das Redes Municipais à dos demais profissionais é 83,8\%" (média Brasil). Em segundo lugar, complementarmente, o Quadro $3^{8}$, abaixo, informa que o investimento por aluno/ano na educação infantil foi, em 2014, de 21,6\%. 


\section{Quadro 3 - Percentual do Investimento Público Direto por Estudante em relação ao} PIB per capita (\%)

\begin{tabular}{|c|c|c|c|c|c|c|c|}
\hline \multirow{2}{*}{ Ano } & \multirow{2}{*}{$\begin{array}{c}\text { Todos os } \\
\text { níveis de } \\
\text { ensino }\end{array}$} & \multirow{2}{*}{$\begin{array}{c}\text { Educação } \\
\text { Básica }\end{array}$} & \multirow{2}{*}{$\begin{array}{l}\text { Educação } \\
\text { Infantil }\end{array}$} & \multicolumn{2}{|c|}{$\begin{array}{c}\text { Ensino } \\
\text { Fundamental }\end{array}$} & \multirow[t]{2}{*}{$\begin{array}{l}\text { Ensino } \\
\text { Médio }\end{array}$} & \multirow[t]{2}{*}{$\begin{array}{l}\text { Educação } \\
\text { Superior }\end{array}$} \\
\hline & & & & $\begin{array}{l}1^{\text {a a } 4^{\mathrm{a}}} \\
\text { série }\end{array}$ & $\begin{array}{l}5^{\mathrm{a}} \text { a } 8^{\mathrm{a}} \\
\text { série }\end{array}$ & & \\
\hline 2000 & 14,1 & 11,7 & 14,8 & 11,2 & 11,8 & 11,3 & 128,5 \\
\hline 2001 & 14,4 & 12,0 & 13,1 & 11,0 & 12,7 & 12,6 & 125,7 \\
\hline 2002 & 14,4 & 11,9 & 12,3 & 13,0 & 12,3 & 8,5 & 117,1 \\
\hline 2003 & 13,6 & 11,4 & 13,5 & 12,1 & 11,4 & 9,1 & 98,5 \\
\hline 2004 & 13,8 & 11,8 & 13,0 & 13,1 & 12,2 & 7,9 & 89,1 \\
\hline 2005 & 14,2 & 12,0 & 11,7 & 13,6 & 12,7 & 8,1 & 92,9 \\
\hline 2006 & 16,0 & 13,9 & 12,1 & 14,4 & 15,8 & 10,7 & 90,9 \\
\hline 2007 & 17,5 & 15,3 & 13,8 & 16,0 & 16,8 & 12,2 & 90,3 \\
\hline 2008 & 18,6 & 16,5 & 13,8 & 17,3 & 18,4 & 13,3 & 78,4 \\
\hline 2009 & 20,2 & 17,8 & 13,6 & 19,2 & 20,1 & 13,8 & 86,9 \\
\hline 2010 & 21,4 & 18,8 & 15,4 & 20,2 & 20,2 & 16,0 & 84,8 \\
\hline 2011 & 22,8 & 19,9 & 17,8 & 20,4 & 20,5 & 19,4 & 88,3 \\
\hline 2012 & 24,4 & 21,7 & 21,0 & 22,1 & 21,2 & 22,1 & 80,5 \\
\hline 2013 & 25,8 & 22,8 & 22,6 & 22,9 & 22,7 & 23,0 & 88,9 \\
\hline 2014 & 24,5 & 21,8 & 21,6 & 21,7 & 21,8 & 22,1 & 80,3 \\
\hline 2015 & 25,2 & 22,1 & 22,3 & 21,8 & 21,7 & 23,0 & 80,4 \\
\hline
\end{tabular}

Fonte: Inep/MEC - Tabela elaborada pela Deed/Inep.

Portanto, para cumprir a Meta $17^{9}$ seria necessário elevar em $83,8 \%$ o percentual verificado em 2014 (21,6\%), de forma que. em 2020 (note-se que o tempo previsto para a equiparação é de seis anos), o investimento por aluno/ano em educação infantil/creche teria que alcançar $39,7 \%{ }^{10}$.

Abaixo, é possível ver o investimento a ser feito, ano a ano, por aluno/ano, como percentual do PIB per capita (PPC), de forma a atingir, gradual e linearmente, os 39,7\%.

\begin{tabular}{|c|c|c|c|c|c|c|c|}
\hline Ano & 2014 & 2015 & 2016 & 2017 & 2018 & 2019 & 2020 \\
\hline \%РPC & $21,6 \%$ & $24,6 \%$ & $27,6 \%$ & $30,6 \%$ & $33,6 \%$ & $36,7 \%$ & $39,7 \%$ \\
\hline
\end{tabular}




\section{Qual a relação entre a Meta 17 e o custo aluno qualidade?}

Vale ressaltar que o percentual de 39,7\%, já indicado, é consonante com os cálculos da Campanha pelo Direito à Educação, que propõe o valor de 39,3\% ${ }^{11}$. Ou seja, as formulações da Campanha são inteiramente compatíveis com os objetivos estabelecidos pela Meta 17, levando-se em conta os dados apresentados pelo Dieese em sua Nota Técnica 141.

Há um fato adicional digno de nota, que aqui registramos: o piso salarial do magistério relativo ao ano de 2014, corrigido pela inflação do período 2014-2018 (34,4\%) e pelos $83,8 \%$ (Nota Técnica 141 do Dieese), atingiria um valor muito próximo ${ }^{12}$ do piso salarial da carreira do ensino básico técnico e tecnológico (professores do ensino básico nas Ifes), o que possibilitaria futuramente a construção de uma única carreira de professor (do municipal ao federal).

Portanto, é importante salientar que, para além da relação anunciada no título acima, há basicamente equivalência entre: 1) cumprir a Meta 17 do PNE; 2) alcançar o custo aluno-qualidade, conforme valores pleiteados pela Campanha; e 3) estabelecer um piso salarial isonômico entre os docentes da rede municipal do ensino básico e os professores do ensino básico federal.

\section{Os dados disponíveis apontam para o cumprimento da Meta 17?}

O Quadro 3 (dados publicados pelo Inep/MEC) e o Quadro 4 (valores do investimento por aluno/ano necessários ao cumprimento da Meta 17) mostram, preliminarmente, que a resposta é negativa: o percentual de investimento deveria ter alcançado 24,6\% em 2015, mas ficou em $22,3 \%$.

Como o Governo não publicou dados relativos aos investimentos em educação depois de 2015, é necessário estimar os valores investidos após 2015, indiretamente, sob as seguintes hipóteses: 1) o investimento total por aluno/ano na educação infantil/creche (como percentual do PPC), entre 2015 e 2019, acompanhou a evolução da folha de pessoal (ou seja, o percentual deste último insumo no investimento total foi aproximadamente constante no período); e 2) a folha de pessoal, nesse mesmo período, acompanhou da mesma forma a evolução do valor do piso salarial do magistério.

Dessa forma, como temos os valores do piso salarial do magistério, ano a ano (de 2015 até 2019), bem como a inflação do período (índice do Dieese), podemos calcular a evolução do valor real do piso e, sob as hipóteses acima, é possível computar, igualmente, a evolução do investimento por aluno/ano (percentual do PPC), a partir de comparação com o valor vigente em 2015 (que é conhecido: 22,3\%). 


\section{Gráfico 2 - Investimento por aluno/ano, EI/Creche (\%PPC)}

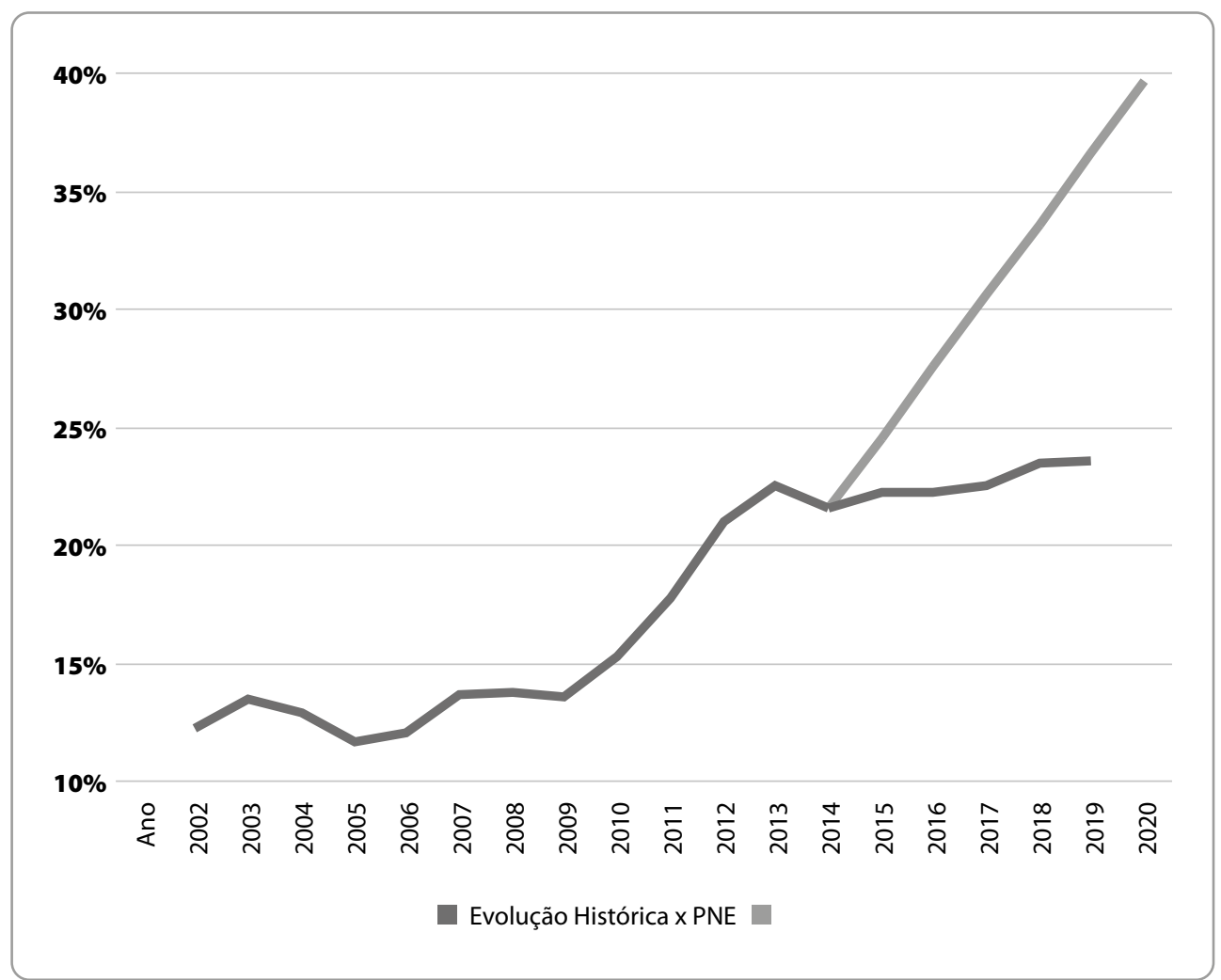

A análise do Gráfico 2 mostra que, a partir de 2005, o investimento por aluno/ano, na educação infantil/creche, iniciou uma trajetória de elevação constante, passando de menos de $12 \%$ para quase $23 \%$, em 2013 , ou seja, quase dobrando num período de oito anos. Nesse ritmo, seria possivelmente alcançado, em 2020, o percentual de 40\%, atingindo-se o custo aluno-qualidade almejado e, também, cumprindo-se a Meta 17. Entretanto, a partir de 2013 até o presente ano, o percentual ficou estagnado. Considerando-se esse dado e a política defendida e praticada pelo atual Governo, é virtualmente impossível a reversão dessa situação no próximo ano, com uma subida vertiginosa de $24 \%$ para $40 \%$. É altamente provável, pois, que a Meta 17 venha a ser descumprida por larga margem.

\section{O descumprimento das metas 1 e 17 e de todo o PNE}

A aprovação da EC 95, em 2016, obriga a União a reduzir progressivamente, em termos de percentual do PIB, os investimentos no setor público. Uma consulta ao Orçamento 
da União mostra que as áreas que concentram esses investimentos são a Previdência e as ofertas de serviços como saúde e educação.

Em que proporção deverão ser contraídas essas 'despesas', de acordo com a EC 95? Para avaliar a questão relativa à necessária (de acordo com esse modelo) contração do repasse de recursos para as áreas sociais, tomaremos por base o documento Impactos do "Novo Regime Fiscal", produzido por consultoria da Câmara dos Deputados ${ }^{13}$ para subsidiar a votação da então PEC 247 (que veio a se transformar posteriormente na EC 95). A partir dos valores aí constantes, atualizados no tocante aos anos de 2016, 2017 e 2018, no que diz respeito ao PIB e ao IPCA ${ }^{14}$, além de inseridas projeções de ambos para $2019^{15}$, é possível construir o Quadro 5.

\section{Quadro 4 - Parâmetros e indicadores macroeconômicos selecionados, 2001-2025 (cenário de referência)}

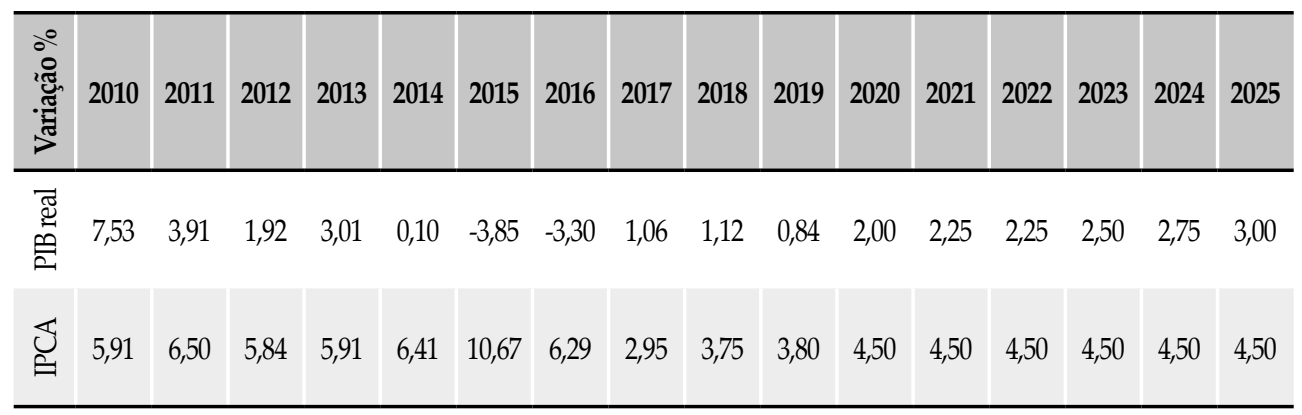

De 2016 em diante, portanto, com a aprovação da EC 95, as destinações de recursos não financeiros - correspondentes às Despesas Primárias Líquidas ${ }^{16}$ (despesas previdenciárias e as relativas à saúde e à educação, dentre outras) - ficaram limitadas, em valor real, às do ano anterior. Consequentemente, com a expansão do PIB prevista no Quadro 5, essas destinações, como percentual do PIB, terão que declinar, ano a ano, enquanto vigorar a EC 95. Para melhor compreensão da evolução histórica das destinações de recursos financeiros, bem como da trajetória futura (pós 2016) imposta pela EC 95, apresentamos, no Quadro 6, dados referentes ao PIB, às Receitas Primárias Líquidas ${ }^{17}$ (RPL), às Despesas Primárias Líquidas (DPL), aos Benefícios Previdenciários ${ }^{18}(\mathrm{BP})$ e aos Juros ${ }^{19}$ (JDP) pagos sobre a Dívida Pública Federal ${ }^{20}$ (DPF). No período que vai de 2008 a 2018, os dados estão consolidados; já os valores relativos a 2019 são projeções e estimativas, posto que o ano está ainda em curso. 


\section{Quadro 5}

\begin{tabular}{|c|c|c|c|c|c|c|c|c|c|c|c|c|}
\hline \multirow{2}{*}{ 宗 } & \multirow{2}{*}{$\begin{array}{l}\text { PIB } \\
\text { (R\$ } \\
\text { bi) }\end{array}$} & \multirow{2}{*}{$\begin{array}{c}\text { RPL } \\
\text { (R\$ } \\
\text { bi) }\end{array}$} & \multirow{2}{*}{$\begin{array}{l}\text { RPL/ } \\
\text { PIB }\end{array}$} & \multirow{2}{*}{$\begin{array}{c}\text { DPL } \\
\text { (R\$ } \\
\text { bi) }\end{array}$} & \multirow{2}{*}{$\begin{array}{l}\text { DPL/ } \\
\text { PIB }\end{array}$} & \multirow{2}{*}{$\begin{array}{l}\text { BP } \\
\text { (R\$ } \\
\text { bi) }\end{array}$} & \multirow{2}{*}{$\begin{array}{l}\text { BP/ } \\
\text { PIB }\end{array}$} & \multirow{2}{*}{$\begin{array}{c}\text { DPLas/ } \\
\text { PIB }\end{array}$} & \multirow{2}{*}{$\begin{array}{c}\text { DPF } \\
\text { (R\$ } \\
\text { bi) }\end{array}$} & \multirow{2}{*}{$\begin{array}{l}\text { DPF/ } \\
\text { PIB }\end{array}$} & \multirow{2}{*}{$\begin{array}{l}\text { JDP } \\
\text { (R\$ } \\
\text { bi) }\end{array}$} & \multirow{2}{*}{$\begin{array}{l}\text { JP/ } \\
\text { PIB }\end{array}$} \\
\hline & & & & & & & & & & & & \\
\hline 2008 & 3109,8 & 588 & $18,9 \%$ & 522,4 & $16,8 \%$ & 199,6 & $6,4 \%$ & $10,4 \%$ & 1397,3 & $44,9 \%$ & 110,2 & $3,5 \%$ \\
\hline 2009 & 3333 & 618,1 & $18,5 \%$ & 609,9 & $18,3 \%$ & 224,9 & $6,7 \%$ & $11,6 \%$ & 1497,4 & $44,9 \%$ & 124,6 & $3,7 \%$ \\
\hline 2010 & 3885,8 & 785 & $20,2 \%$ & 691,7 & $17,8 \%$ & 254,9 & $6,6 \%$ & $11,2 \%$ & 1694 & $43,6 \%$ & 122,4 & $3,2 \%$ \\
\hline 2011 & 4373,7 & 825,1 & $18,9 \%$ & 756,6 & $17,3 \%$ & 281,4 & $6,4 \%$ & $10,9 \%$ & 1866,4 & $42,7 \%$ & 131,1 & $3,0 \%$ \\
\hline 2012 & 4805,9 & 888,2 & $18,5 \%$ & 869,9 & $18,1 \%$ & 316,6 & $6,6 \%$ & $11,5 \%$ & 2008 & $41,8 \%$ & 135,1 & $2,8 \%$ \\
\hline 2013 & 5316,5 & 997,4 & $18,8 \%$ & 983,5 & $18,5 \%$ & 357 & $6,7 \%$ & $11,8 \%$ & 2122,8 & $39,9 \%$ & 141,7 & $2,7 \%$ \\
\hline 2014 & 5687,3 & 1023,1 & $18,0 \%$ & 1080,6 & $19,0 \%$ & 402,1 & $7,1 \%$ & $11,9 \%$ & 2295,9 & $40,4 \%$ & 170 & $3,0 \%$ \\
\hline 2015 & 5904,3 & 1043.7 & $17,7 \%$ & 1151,5 & $19,5 \%$ & 436,1 & $7,4 \%$ & $12,1 \%$ & 2793 & $47,3 \%$ & 225,2 & $3,8 \%$ \\
\hline 2016 & 6266 & 1088 & $17,4 \%$ & 1211,3 & $19,3 \%$ & 498,5 & $8,0 \%$ & $11,4 \%$ & 3112,9 & $49,7 \%$ & 304,1 & $4,9 \%$ \\
\hline 2017 & 6554 & 1154,7 & $17,6 \%$ & 1286,3 & $19,6 \%$ & 557,2 & $8,5 \%$ & $11,1 \%$ & 3559,3 & $54,3 \%$ & 339,1 & $5,2 \%$ \\
\hline 2018 & 6827 & 1227,5 & $18,0 \%$ & 1317,5 & $19,3 \%$ & 586,4 & $8,6 \%$ & $10,7 \%$ & 3877,1 & $56,8 \%$ & 387,2 & $5,7 \%$ \\
\hline 2019 & 7280 & 1307,2 & $18,0 \%$ & 1387 & $19,1 \%$ & 637,9 & $8,8 \%$ & $10,3 \%$ & 4300 & $59,1 \%$ & 378,9 & $5,2 \%$ \\
\hline
\end{tabular}

$\mathrm{RPL}=$ Receitas Primárias Líquidas. DPL = Despesas Primárias Líquidas. DPLas = Despesas Primárias Líquidas não previdenciárias. $\mathrm{BP}=$ Benefícios Previdenciários. DPF = Dívida Pública Federal. JDP=Juros da Dívida Pública Federal.

As DPL (2008-2019) totais, previdenciárias e não previdenciárias, podem ser vistas no Gráfico 3:

\section{Gráfico 3: Despesas Primárias Líquidas (totais, previdenciárias e não previdenciárias)}

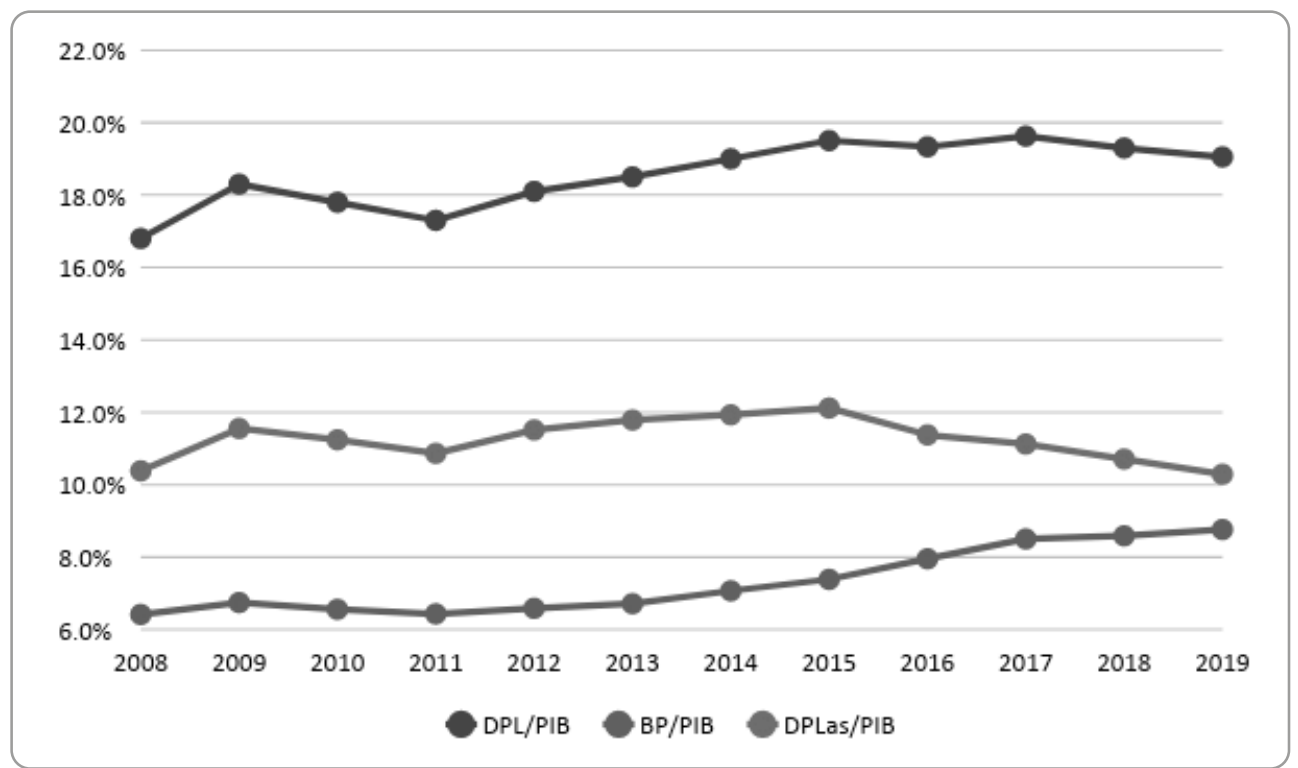


Já as DPL (totais) no período 2008-2019 e a trajetória que terão que seguir na década seguinte, fruto da vigência da EC 95, podem ser visualizadas no Gráfico 4:

\section{Gráfico 4 - Impacto da EC 95}

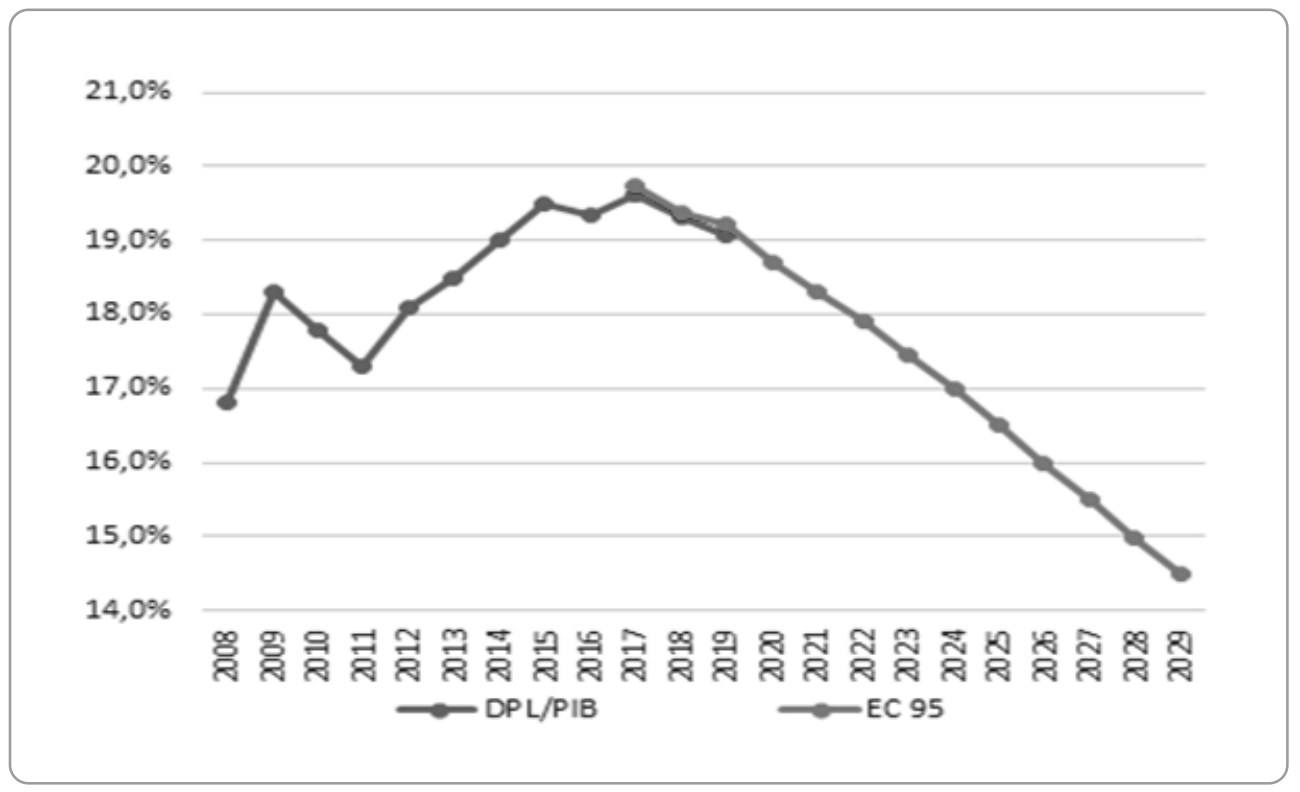

Como se pode ver no Gráfico 4, serão retirados das áreas sociais, em 2029, mais de $5 \%$ do PIB; o total de recursos subtraídos da previdência, educação, saúde, etc. deve se aproximar, na década vindoura, de 30\% do PIB, ou cerca de $\mathrm{R} \$ 2$ trilhões (o PIB de 2018 foi em trono de $\mathrm{R} \$ 6,8$ trilhões).

O cenário que se desenha, que é o do referendo no Senado Federal, com pequenas modificações da Reforma da Previdência já aprovada na Câmara dos Deputados, aponta para um 'economia' um pouco superior a $R \$ 0,9$ trilhões na previdência, o que significa que algo em torno de $R \$ 1,1$ trilhão deverá ser retirado da educação, saúde e outras áreas.

Os $R$ \$ 2 trilhões em questão serão direcionados ao pagamento dos rentistas, a juros reais, que, apesar de reduzidos recentemente, continuam entre os maiores do planeta. As "reformas" implementadas e os cortes nas áreas de educação e nas demais são, pois, parte de um processo de transferência de renda dos setores menos favorecidos da sociedade para os mais favorecidos, agudizando a profunda desigualdade já existente.

O Gráfico 5 visualiza esse cenário. 


\section{Gráfico 5: Impacto da EC 95}

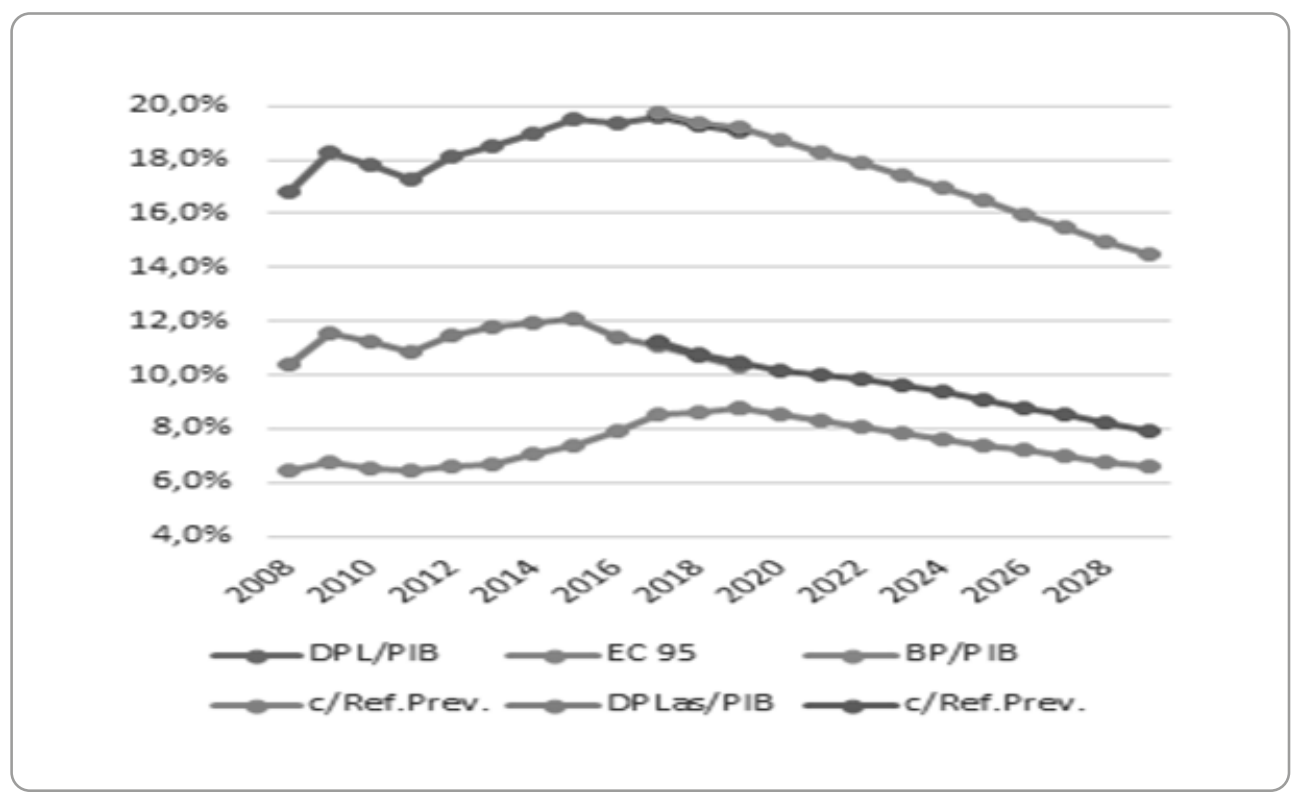

A curva azul, que continua com a vermelha, representa a trajetória das DPL, caso continue em vigor a EC 95. A curva azul clara, que continua com a verde, representa a trajetória das DPL nas áreas sociais - redução do porte de quase 30\%. E a curva cinza, que continua com a amarela, representa a trajetória dos BP.

\section{Conclusão}

Os dados mostram que a Meta 1 e a Meta 17 não serão cumpridos, com altíssima probabilidade. Isso significa que não haverá a oferta de educação infantil e nem a valorização dos profissionais do magistério previstos nas respectivas metas. E nem tampouco será implantado o correspondente custo aluno-qualidade.

Fica igualmente claro que a continuidade da vigência da EC 95, que prevê uma redução da ordem de $25 \%$ a $30 \%$ nos recursos a serem destinados às áreas sociais, impactará em índices similares a educação e, nesse cenário, produzirá uma contração dos recursos destinados à área, que cairão de 6,5\% do PIB (em 2015) para menos de 5\%, em uma década, inviabilizando todas as metas do PNE. Em particular, serão irreversivelmente comprometidas as redes de universidades e institutos federais, patrimônio do povo brasileiro, bem como a produção de conhecimento de excelência e a formação de profissionais altamente qualificados que aí se desenvolvem. 


\title{
É hora de união de todos os que defendem uma educação pública de qualidade,
} universal e inclusiva. É fundamental e urgente convencer a sociedade brasileira de que é necessário reverter esse caminho sem futuro, antes que não tenha volta.

\author{
Recebido em 10.10.2019 e Aprovado em 24.10.2019
}

\section{Notas}

1 A estratégia 20.6) do PNE prevê que: "no prazo de 2 (dois) anos da vigência deste PNE, será implantado o Custo Aluno-Qualidade inicial (CAQi), referenciado no conjunto de padrões mínimos estabelecidos na legislação educacional e cujo financiamento será calculado com base nos respectivos insumos indispensáveis ao processo de ensino-aprendizagem e será progressivamente reajustado até a implementação plena do Custo Aluno Qualidade (CAQ)".

2 “Meta 17: valorizar os(as) profissionais do magistério das redes públicas de educação básica de forma a equiparar seu rendimento médio ao dos(as) demais profissionais com escolaridade equivalente, até o final do sexto ano de vigência deste PNE."

3 "Meta 1: universalizar, até 2016, a educação infantil na pré-escola para as crianças de 4 (quatro) a 5 (cinco) anos de idade e ampliar a oferta de educação infantil em creches de forma a atender, no mínimo, 50\% (cinquenta por cento) das crianças de até 3 (três) anos até o final da vigência deste PNE."

4 Os dados utilizados neste trabalho correspondem às 'Projeções 2013' (2000-2060) do Instituto Brasileiro de Geografia e Estatística (IBGE) e estão disponíveis (acesso em 29/09/2019) na página: https://www.ibge.gov. br/estatisticas/sociais/populacao/9109-projecao-da-populacao.html?edicao=9116\&t=resultados.

5 Os dados relativos ao número de matrículas (públicas e privadas) no ensino infantil - creche foram obtidos nas 'Sinopses Estatísticas da Educação Básica', disponíveis na página do Inep/MEC.

6 Nota Técnica 141 / Dieese, “Transformações recentes no perfil do docente das escolas estaduais e municipais da educação básica", disponível (acesso em 29/09/2019) em: https:/www.dieese.org.br/notatecnica/2014/notaTec141DocentesPnadvf.html.

7 Fonte: IBGE. Pnad. Microdados de 2002, 2006, 2011 e 2013; ocupações selecionadas: 2311, 2312, 2313, 2321, 2330, 2391, 2392, 3311, 3312, 3313, 3321, 3322 e 3331.

8 Fonte: Inep/MEC, página (acesso em 30/09/2019) http://inep.gov.br/indicadores-financeiros-educacionais Essa é a informação mais atualizada disponível; não foram publicadas atualizações após 2015.

9 Supõe-se, como hipótese, que o percentual do insumo 'Folha de Pessoal' permaneça constante em relação ao investimento total necessário por aluno/ano.

10 O cálculo aqui é: $21,6 \% 8(1,838)=39,7 \%$.

11 De acordo com a apresentação da Campanha Nacional pelo Direito à Educação ao Senado Federal, intitulada “CAQi-CAQ no PNE e Parecer CNE/CEB 8/2010”, disponível (acesso 30/09/2019) em legis.senado.leg. br, seria necessário investir 39,3\% do PIB per capita em cada aluno do ensino infantil/creche.

12 O piso salarial do magistério foi, em 2014, de R\$ 1.697,39. A inflação no período 2014-2018, medida pelo Dieese, alcançou 34,4\%. E o índice a ser aplicado para a equiparação estipulada pela Meta 17 (segundo a Nota Técnica 141 do Dieese) deveria ser de 83,8\% Portanto, R $\$ 1.697,37 \times 1,344 \times 1,838=\mathrm{R} \$ 4.192,00$. Por outro lado, o salário do professor graduado, dedicação exclusiva, da carreira do ensino básico técnico e tecnológico (EBTT), que leciona nas redes de universidades e institutos federais era, em janeiro de 2019, R\$ 4.464,00. 
13 Consultoria de Orçamento e Fiscalização Financeira, Câmara dos Deputados. Impactos do "Novo Regime Fiscal": Subsídios à análise da Proposta de Emenda Constitucional, PEC 241/16. Estudo Técnico n.o $12 / 2016$.

14 Os valores da série histórica do IPCA, incluindo os anos de 2016/17/18, podem ser obtidos no sítio do IBGE, https:/www.ibge.govtisticas/economicas/precos-e-custos/9256-indice-nacional-de-precos-ao-consumidor-amplo.html?=\&t=series-historicas.br/esta.

15 Já as projeções para o IPCA e PIB de 2019, respectivamente 3,8\% e 0,84\%, estão disponíveis nos relatórios de mercado Focus de 29/07/2019, em https://www.em.com.br/app/noticia/economia/2019/07/29/internas_economia,1073123/projecao-para-pib-de-2019-permanece-em-alta-de-0-82-na-pesquisa-focus.shtml e https:// economia.estadao.com.br/noticias/geral,projecao-do-ipca-para-2019-passa-de-3-78-para-3-80-aponta-focus,70002944993.

16 As Despesas Primárias Líquidas resultam das Despesas Primárias (que correspondem basicamente aos gastos do Governo para manter suas atividades e investir em ações novas) quando se descontam as Transferências Constitucionais. Os dados podem ser obtidos nas mesmas fontes que as das RPL (abaixo).

17 As Receitas Primárias Líquidas resultam das Receitas Primárias (que correspondem basicamente aos tributos arrecadados) quando se descontam as Transferências Constitucionais. Os dados apresentados aqui podem ser obtidos nos RAF, Relatórios de Acompanhamento Fiscal, produzidos pelo Senado Federal e publicados pela Instituição Fiscal Independente (Senado Federal) - acessar https://www12.senado.leg.br/ ifi/relatorio-de-acompanhamento-fisca Os valores da série histórica, desde 2002, podem ser obtidos no sítio da Câmara Federal, https://www2.camara.leg.br/orcamento-da-uniao/orcamento-da-uniao-em-foco/ web-orcamento-em-foco-2018

18 Fontes para os dados apresentados são sítios e tabelas produzidos pelo Senado Federal - consultar www2. senado.leg.br/bdsf/bitstream/handle/id/556198/RAF27_ABR2019_Despesas_RGPS.pdf - bem como Tesouro Nacional, tais como http://www.tesouro.fazenda.gov.br/documents/10180/0/Relatório+da+Previdência+editado/

19 Fonte de dados para os juros da Dívida Pública Federal são as publicações 'Orçamento Cidadão' - veja a de 2017: www.orcamentofederal.gov.br/clientes/portalsof/portalsof/orcamentos-anuais/orcamento-2017/ ploa/ploa-2017-orcamento-cidadao

20 Os dados relativos à DPF podem ser obtidos na página do Tesouro Nacional (acessar o ano de interesse): http://www.tesourotransparente.gov.br/publicacoes/relatorio/relatorio-anual-da-divida-rad/publicacao-2019-02-20-8000709302.

\section{Referências}

BRASIL. Emenda Constitucional no 95, de 15 de dezembro de 2016. Institui o Novo Regime Fiscal e dá outras providências. Brasília: Senado Federal, 2016. Disponível em https://www2.camara.leg.br/legin/fed/ emecon/2016/emendaconstitucional-95-15-dezembro-2016-784029-publicacaooriginal-151558-pl.html Acesso em 30/09/2019 Acesso em 30/09/2019.

BRASIL. Lei n⿳0 13.005, de junho de 2014. Aprova o Plano Nacional de Educação - PNE e dá outras providências. Brasília: Senado Federal, 2014. Disponível em http://pne.mec.gov.br/ Acesso em 30/09/2019.

CÂMARA DOS DEPUTADOS, CONSULTORIA DE ORÇAMENTO E FISCALIZAÇÃO FINANCEIRA. Impactos do “Novo Regime Fiscal”: Subsídios à análise da Proposta de Emenda Constitucional, PEC 241/16. Estudo Técnico n.ํㅜ 12/2016. Brasília: CÂMARA DOS DEPUTADOS, 2016.

CÂMARA DOS DEPUTADOS, Orçamento da União. Brasília, CÂMARA DOS DEPUTADOS, 2018. Disponível em https://www2.camara.leg.br/orcamento-da-uniao/orcamento-da-uniao-em-foco/web-orcamento-emfoco-2018 Acesso em 30/09/2019. 
CAMPANHA NACIONAL PELO DIREITO À EDUCAÇÃO (CNDE), CAQi-CAQ no PNE e Parecer CNE/CEB 8/2010. Brasília: CNDE, 2010. Disponível em legis.senado.leg.br Acesso em 30/09/2019.

DEPARTAMENTO INTERSINDICAL DE ESTATÍSTICA E ESTUDOS SOCIOECONÔMICOS (DIEESE), Nota Técnica 141 / DIEESE, “Transformações recentes no perfil do docente das escolas estaduais e municipais da educação básica" Brasília: DIEESE, 2014. Disponível em https://www.dieese.org.br/ notatecnica/2014/notaTec141DocentesPnadvf.html Acesso em 30/09/2019.

FOCUS, PESQUISA DE MERCADO. PIB de 2019 permanece em alta. São Paulo: FOCUS, 2019. Disponível em $h$ ttps://www.em.com.br/app/noticia/economia/2019/07/29/internas_economia,1073123/projecaopara-pib-de-2019-permanece-em-alta-de-0-82-na-pesquisa-focus.shtml e https://economia.estadao.com.br/noticias/ geral,projecao-do-ipca-para-2019-passa-de-3-78-para-3-80-aponta-focus,70002944993 Acesso em 30/09/2019.

INSTITUIÇÃO FISCAL INDEPENDENTE (IFI), SENADO FEDERAL. Relatório de Acompanhamento Fiscal. Brasília: IFI, 2019. Disponível em https://www12.senado.leg.br/ifilrelatorio-de-acompanhamento-fisca Acesso em 30/09/2019.

INSTITUTO BRASILEIRO DE GEOGRAFIA E ESTATÍSTICA (IBGE). Pnad. Microdados de 2002, 2006, 2011 e 2013. Brasília: 2002, 2005, 2011 e 2013.

INSTITUTO BRASILEIRO DE GEOGRAFIA E ESTATÍSTICA (IBGE). Projeções 2013, 2000-2060. Brasília: IBGE, 2013. Disponível em https://www.ibge.gov.br/estatisticas/sociais/populacao/9109-projecao-da-populacao. html?edicao=9116\&t=resultados Acesso em 30/09/2019.

INSTITUTO BRASILEIRO DE GEOGRAFIA E ESTATÍSTICA (IBGE). Série histórica do IPCA. Brasília: IBGE, 2019. Disponível em $h$ ttps://www.ibge.govtisticas/economicas/precos-e-custos/9256-indice-nacional-deprecos-ao-consumidor-amplo.html?=Et=series-historicas.br/esta Acesso em 30/09/2019.

INSTITUTO NACIONAL DE ESTUDOS E PESQUISAS EDUCACIONAIS ANÍSIO TEIXEIRA (INEP), Sinopses Estatísticas da Educação Básica. Brasília: MEC/INEP, 2000 a 2018. Disponível em http://inep.gov. br/sinopses-estatisticas-da-educacao-basica Acesso em 30/09/2019.

MINISTÉRIO DA EDUCAÇÃO (MEC), Indicadores financeiros educacionais. Brasília: MEC/INEP, 2002 a 2015. Disponível em http://inep.gov.br/indicadores-financeiros-educacionais Acesso em 30/09/2019.

MINISTÉRIO DO PLANEJAMENTO, ORÇAMENTO E GESTÃO (MPOG). Orçamento Cidadão. Brasília: MPOG, 2017. Disponível em www.orcamentofederal.gov.br/clientes/portalsof/portalsof/orcamentosanuais/orcamento-2017/ploa/ploa-2017-orcamento-cidadao Acesso em 30/09/2019.

SENADO FEDERAL. Despesas com o Regime Geral de Previdência Social. Brasília: SENADO FEDERAL, 2019. Disponível em www2.senado.leg.br/bdsflbitstream/handle/id/556198/RAF27_ABR2019_ Despesas_RGPS.pdf Acesso em 30/09/2019.

TESOURO NACIONAL. Relatório da Previdência. Brasília: TESOURO NACIONAL, 2018. Disponível em $h$ ttp://www.tesouro.fazenda.gov.br/documents/10180/0/Relatório+da+Previdência+editado/ Acesso 30/09/2019.

TESOURO NACIONAL. Tesouro Transparente. Brasília: TESOURO NACIONAL, 2019.

Disponível em http://www.tesourotransparente.gov.br/publicacoes/relatorio/relatorio-anual-da-divida-rad/ publicacao-2019-02-20-8000709302 Acesso em 30/09/2019. 